\title{
Management Pengoptimalan Kebutuhan Oksigen Pada Pasien Gagal Jantung Di Unit Perawatan Intensif: A Literatur Review
}

\author{
Linggar Pangukir Rahayu ${ }^{1^{*}}$ \\ ${ }^{1}$ Mahasiswa Profesi Ners Universitas Muhamammadiyah Surakarta, Kartasura, 57162, Jawa Tengah, \\ Indonesia \\ *Korespodensi: Linggarsugianto@gmail.com
}

\begin{abstract}
Abstrak: Gagal jantung terjadi dengan gejala yang berhubungan dengan gangguan fungsi ventrikel miokard selain itu gagal jantung bermanifestasi sebagai kongesti vaskuler dalam sirkulasi paru dan sistemik sehingga menghasilkan gejala ketidakcukupam sirkulasi. Penanganan utama pada pasien gagal jantung dengan mencukupi kebutuhan oksigenasi. Tujuan: untuk mengetahui cara mengoptimalkan kebutuhan oksigen pasien gagal jantung. Metode: penelitian ini menggunakan metode literatur review yang berfokus pada pemenuhan kebutuhan oksigen pasien gagal jantung dengan melakukan penelusuran di Google Scholar, Elsevier, dan Pubmed dengan menggunakan kata kunci gagal jantung, oksigenasi, respirasi, heart failure, respiratory, dan heart rate dalam kurun waktu 2015 - 2020. Hasil: pencarian mendapatkan lebih dari 500 case report sesuai dengan kata kunci lalu dilakukan penyaringan didapatkan 5 artikel case report. Jurnal tersebut menjelaskan tentang kasus pasien gagal jantung dan cara mengatasi kebutuhan oksigen pada pasien gagal jantung yang sering mengalami sesak nafas atau hipoksemia. Kesimpulan: terapi oksigenasi pasien gagal jantung dapat dilakukan dengan menggunakan alat bantu ventilasi dan pengaturan posisi pasien sesuai dengan kondisi dan komplikasi pasien.
\end{abstract}

Kata kunci: Gagal jantung, oksigenasi, heart rate.

Abstract: Heart failure occurs with symptoms associated with an impaired myocardial ventricular function other than that heart failure manifests as vascular congestion in the pulmonary and systemic circulation resulting in symptoms of insufficient circulation. The main treatment in patients with heart failure with sufficient oxygenation needs. Objective: to find out how to optimize the oxygen needs of heart failure patients. Method: This study uses a literature review method that focuses on fulfilling the oxygen needs of heart failure patients by searching Google Scholar, Elsevier, and Pubmed by using keywords heart failure, oxygenation, respiratory, and heart rate in the period 2015 -2020. Results: the search found more than 500 case reports according to keywords and then filtered, obtained 5 case report articles. The journal describes the case of heart failure patients and how to cope with oxygen demand in heart failure patients who often experience shortness of breath or hypoxemia. Conclusion: oxygenation therapy for heart failure patients can be done by using ventilation aids and adjusting the patient's position according to the patient's condition and complications.

Keywords: Heart failure, oxygenation, heart rate. 


\section{PENDAHULUAN}

Gagal jantung adalah keadaan dimana ketidakmampuan jantung dalam mempertahanakan sirkulasi yang cukup bagi kebutuhan tubuh, meskipun tekanan darah pada vena adekuat (Mugihartadi \& Handayani, 2020). Gagal jantung terjadi dengan gejala yang berhubungan dengan gangguan fungsi ventrikel miokard selain itu gagal jantung bermanifestasi sebagai kongesti vaskuler dalam sirkulasi paru dan sistemik sehingga menghasilkan gejala ketidakcukupam sirkulasi. Gagal jantung memiliki beberapa faktor resiko. Faktor resiko yang dapat dirubah meliputi hipertensi, coronary artery disease, diabetes, aritmia, congenital heart defect, memiliki riwayat infark miokardial dan kardiomipati. Sedangkan faktor resiko yang dapat diubah yaitu merokok, obesitas, hiperlipidemia, dan juga status sosioekonomi dapat mengakibatkan terjadinya gagal jantung (Study \& Gheorghiu, 2017).

Menurut Mugihartadi \& Handayani (2020) gagal jantung terjadi seiring bertambahnya usia dan sering terjadi pada pasien dengan usia sekitar lebih dari 65 tahun dengan persentasi $6-10 \%$ lebih banyak terjadi pada laki laki daripada perempuan. Gagal jantung dapat terjadi pada siapa saja terutama bagi mereka yang mengalami penurunan kesehatan, misalnya orang dewasa dan lansia (Study \& Gheorghiu, 2017). Gagal jantung berkaitan dengan adanya perubahan umum yang berhubungan dengan usia dalam struktur dan fungsi kardiovaskuler. Perubahan tersebut dapat mengurangi respon kronotropik dan inotropik, meningkatkan tekanan intrakardiak dengan pengisian ventrikel, dan meningkatkan afterload. Akibat dari hal tersebut, kemampuan jantung untuk merespon stres terganggu, baik stres fisiologis maupun patologis (misalnya iskemia atau sepsis miokard). Kondisi kardiovaskular yang menurun mencerminkan adanya pengurangan pemasukan oksigen. (Dharmarajan \& Rich, 2017).

Penanganan yang utama pada pasien gagal jantung yaitu dengan mencukupi kebutuhan oksigenasi. Telah banyak studi yang memuat penanganan pasien gagal jantung yang tepat dan cepat, salah satunya management pengoptimalan kebutuhan oksigen pasien baik menggunakan alat bantu ventilasi maupun pengaturan posisi pasien. Berdasarkan ulasan tersebut, penulis perlu melakukan studi literatur terkait management pengoptimalan kebutuhan oksigen pasien gagal jantung yang berada di unit perawatan intensif.

\section{METODE}

Metode penelitian yang digunakan pada penelitian ini yaitu literatur review dengan tipe studi yang akan diidentifikasi yaitu case report. Penulisan studi literatur dilakukan dengan melakukan penelusuran melalui situs jurnal terakreditasi seperti Elsevier, Google Scholar, serta Pubmed. Kata kunci yang digunakan pada penelusuran diantaranya gagal jantung, oksigenasi, respirasi, heart failure, respiratory, dan heart rate dalam kurun waktu 2015 - 2020. Artikel yang digunakan yaitu artikel Bahasa Inggris dan Bahasa Indonesia dengan tanggal publikasi 5 tahun terakhir dimulai dari tahun 2015 sampai tahun 2020 dalam bentuk full teks

\section{HASIL}

\section{Gambaran Kasus A}

Pasien Ny. X usia 73 tahun datang ke IGD, 7 hari sebelumnya pasien mengeluh dispnea progresif, ortopnea, dan nyeri dada pleuritik. Pasien memiliki riwayat diabetes mellitus tipe 2 dan gagal jantung kongestif iskemik. Pemeriksaan fisik didapatkan pasien pucat, pernafasan sedang menggunakan otot bantu pernafasan, tekanan darah $110 / 65 \mathrm{mmHg}$, nadi $122 \mathrm{kali} /$ menit, respirasi rate $30 \mathrm{kali} /$ menit, dan suhu $37,9^{\circ} \mathrm{C},{\mathrm{S} a \mathrm{O}_{2}}_{2} 77 \%$, hasil auskultasi paru menunjukkan ronki kasar bagian tengah bilateal, hasil analisis gas darah arteri awal menunjukkan pH 7, 44, pCO2 $35 \mathrm{mmHg}$ dan $\mathrm{PO} 2$ $46 \mathrm{mmHg}$. Hasil laboratorium pasien menunjukkan anemia dengan hemoglobin 9,8 g/dL (normal 11,5 - 15), leukosit 14, $7 \times 10^{3} / \mathrm{mm}^{3}$ (normal $4-10 \times 10^{3}$ ). Hasil radiografi dada menunjukkan penebalan interstitial dan kardiomegali kemudian pasin diduga mengalami dekompensasi gagal jantung kronis 
kemudian pasien dirawat di ICU. Pasien mendapatkan terapi diuretik, antibiotik intravena (asam amoksisilin - klavulanat dengan levoflaxacin) dan ventilasi mekanik intensif CPAP. Setelah dilakukan pengkajian lebih lanjut, peneliti awalnya menduga pasien mengalami emboli paru akut namun hasil CTPA menunjukkan adanya trombus besar yang menghalangi vena paru superior kiri, efusi pleura bilateral, dan kondensasi paru kanan, yang mana trombus vena dianggap idiopatik dan pasien mendapatkan terapi antikoagulasi dengan heparin dosis rendah (El et al., 2017).

\section{Gambaran kasus B}

Pasien laki laki berusia 90 tahun datang ke IGD dengan keluhan odema ekstemitas bawah, gatal, dan kemerahan yang dirasakan pasien beberapa hari sebelum dibawa ke IGD. Pasien memiliki riwayat penyakit arteri koroner, pencangkokan bypass arteri koroner, stenosis aorta moderat, hipertensi, diabetes mellitus tipe 2, nyeri punggung bawah kronis, pnemonia, kanker prostat, dan demensia. Hasil pengkajian didapatkan suhu $39^{\circ} \mathrm{C}$, tekanan darah $142 / 80 \mathrm{mmHg}$, nadi $104 \mathrm{x} / \mathrm{menit}$, dan pernafasan 26x/ menit. Hasil lab darah menunjukkan natrium $145 \mathrm{mEq} / \mathrm{L}$, potasium 5,3 mEq/ L, nitrogen urea darah $37 \mathrm{mg} / \mathrm{dL}$, kreatinin 2,5 mg / dL, jumlah sel darah putih 14.000/ $\mu \mathrm{L}$, hemoglobin $10,8 \mathrm{~g} / \mathrm{dL}$, dan trombosit 125/ $\mu \mathrm{L}$. Kemudian pasien dipindahkan ke unit perawatan progresif dan menerima pemasangan kateter urin untuk mengukur keakuratan cairan. ketika di rawat di PCU pasien mengalami hipertensi dan tingkat BNP berkisar 411 hingga $458 \mathrm{pg} / \mathrm{mL}$ dalam 2 hari berturut turut yang berarti pasien menunjukkan kelebihan cairan. Pasien juga mengalami gangguan pernafasan dengan meningkatnya kebutuhan oksigen dan diberikan oksigen melalui BiPAP sebanyak $10 \mathrm{~L} / \mathrm{menit}$. Kemudian pasien dipindahkan ke ICU untuk pengelolaan ADHF dan gagal pernafasan akut. Di ICU, pengobatan tekanan saluran nafas positif bilateral berlanjut dan diberian infus bumentanide IV untuk diuresis agresif. Diuresis digunakan untuk mencapai keseimbangan cairan -2048mL (Study \& Gheorghiu, 2017).

\section{Gambaran kasus C}

Pasien pria berusia 58 tahun dengan gagal jantung refrakter setelah infark miokard anterior akut yang meluas (MI). Pasien membutuhkan intra - aortic ballon pump dan filtrasi hemodinamik kontinue pada fase akut, dan alat bantu nafas non - invasif positive pressure ventilation untuk dukungan pernafasan. Pasien mengalami dispnea dan kelelahan ketika mendapatkan terapi inotrop intravena dan terapi medis lainnya. Pasien kemudian menerima alat bantu nafas adaptive servo ventilation untuk membantu dan mempertahankan pernafasan pasien. Namun ketika alat tersebut dipasangkan, pasien mengalami penurunan denyut jantung (HR) dari $100 \mathrm{bpm}$ menjadi $80 \mathrm{bpm}$ kemudian pasien mengalami atrial flutter. Setelah itu keadaan pasien semakin memburuk, pasien mengeluh dispnea saat istirahat. Peneliti menduga pasien mengalami bradikardia relatif. Kemudian pasien dipasangkan alat pacu jantung permanen, setelah pemasangan tekanan darah meningkat (82 - $90 \mathrm{mmHg}$ sistolik), kreatinin serum dan BNP menurun (masing-masing 2,2-1,9 mg/ dl dan 820-302 pg/ ml). Hasil ekokardiogram menunjukkan doppler gelombang pulse dari aliran trans mitral memiliki pola restriktif yang menunjukkan peningkatan tekanan end diastolik left ventrikel. Selain itu, penyerapan oksigen puncak selama latihan kardiopulmoner (CPX) meningkat dari 9,6 menjadi 12,5 l / mnt (Nagatomo et al., 2019).

\section{Gambaran kasus D}

Pasien berusia 55 tahun dirawat karena mengalami sesak nafas selama beberapa hari dan hasil elektrokardiogramnya menunjukkan adanya fibrilasi atrium dengan blok ventrikel atrium dan terdapat bradikardia simtomatik, pasien kemudian didiagnosis dilated cardiomyopaty. Selain terjadi disfungsi jantung, pasien mengalami kelemahan pada otot tungkai atas lebih tepatnya terjadi kelemahan pada gluteus maximus. Setelah itu pasien menjalani latihan uji kardiopulmoner terbatas dengan menganalisis gas metabolik. Latihan tersebut menunjukkan adanya penurunan dalam penyerapan oksigen yang ditunjukkan dengan adanya kompromi yang signifikan terhadap toleransi 
latihan dan juga pasien mengalami kelemahan otot pernafasan yang parah. Latihan tersebut dilakukan dengan cara mengevaluasi otot pernafasan dan mengukur tekanan inspirasi maksimal (MIP) dan tekanan ekspirasi maksimal (MEP) (Taya \& Amiya, 2019).

\section{Gambaran Kasus E}

Pasien bernama Tn. P berusia 32 tahun beragama islam dengan diagnosa medis congestive heart failure (CHF). Hasil pengakajian didapatkan pasien compos mentis dengan keadaan umum lemah, pupil isokor, tekanan darah $118 / 70 \mathrm{mmHg}$ frekuensi nafas $25 \mathrm{x} /$ menit suhu $36^{\circ} \mathrm{C}$ pasien tampak menggunakan otot bantu pernafasan, SPO2 98\% serta pasien terpasang kanul nasal $4 \mathrm{~L} /$ menit, CRT $<2$ detik. Saat pengkajian hari ke 2 pasien mengeluh sesak nafas dengan frekuensi nafas 30x/ menit, tampak adanya cuping hidung, dan otot bantu pernafasan. Pasien kemudian diposisikan semifowler dan pemberian oksigen tetap diberikan dengan $4 \mathrm{~L} /$ menit (Mugihartadi \& Handayani, 2020).

\section{PEMBAHASAN}

\section{Kasus A}

Pada kasus A saat pengkajian saturasi oksigen pasien mengalami penurunan yaitu 77\%, tekanan darah 110/65 $\mathrm{mmHg}$, denyut jantung pasien lebih dari normal yaitu $122 \mathrm{x} /$ menit, respirasi rate pasien lebih dari normal yaitu 30x/menit dan mengalami peningkatan suhu tubuh 37,9 (36,5-37,5

). Pasien mendapatkan terapi antikoagulasi dengan heparin dosis rendah dan terapi diuretik, ${ }^{\circ} \mathrm{C}$

antibiotik intravena (asam amoksisilin-klavulanat dengan levofloxacin), dan ventilasi mekanik invasif Continuous Positive Airway Pressure (CPAP) (El et al., 2017).

Menurut Puspita \& Fadil (2020) pasien dengan gagal jantung akut biasanya akan memunculkan salah satu dari enam klasifikasi klinis. Klasifikasi klinis gagal jantung akut yaitu 1) worsening or decompensated chronic heart failure, 2) edema paru akut, 3) gagal jantung hipertensi, 4) syok kardiogenik, 5) gagal jantung kanan terisolasi, 6) sindrom koroner dan gagal jantung. Pada kasus A penyebab gagal jantung yaitu adanya dekompensasi gagal jantung kronis dimana pasien memiliki riwayat gagal jantung kongestif iskemik dan adanya gejala nyeri dada, dispnea, dan ortopnea selama tujuh hari. Pemberian ventilasi non invasif (CPAP, BiPAP) harus dipertimbangkan pada pasien dengan gangguan pernafasan dengan frekuensi nafas $>25 \mathrm{kali} /$ menit dan $\mathrm{SpO} 2<90 \%$, pada kasus dijelaskan bahwa pasien mengalami penurunan saturasi oksigen hingga 77\% dan frekuensi nafas pasien $30 \mathrm{kali} /$ menit dan pasien mendapatkan bantuan ventilassi mekanik non invasif CPAP untuk memperbaiki gangguan pernafasan dan memenuhi kebutuhan oksigen. Pemakaian alat bantu ventilasi mekanik juga harus terus dipantau karena jika terjadi kegagalan pernafasan dapat menyebabkan terjadinya hipoksemia $(\mathrm{PaO} 2<60 \mathrm{mmHg}(8,0 \mathrm{kPa}))$, hypercapnia $(\mathrm{PaCO} 2>50 \mathrm{mmHg}(6,65 \mathrm{kPa}))$ dan asidosis $(\mathrm{pH}$ $<7,35)$ sehingga pada saat pasien mengalami hal tersebut penggunaan ventilasi non invasif diganti dengan intubasi endotrakeal.

Pada kasus dijelaskan bahwa pasien mengalami trombosis vena paru yang dianggap idiopatik, trombosis vena paru salah satu diagnosa yang jarang ditemukan dalam praktik klinis dan dapat mengancam jiwa seseorang. Trombosis vena paru merupakan kejadian yang jarang terjadi karena jaringan pembuluh darah vena yang kaya akan oksigen mengalir ke paru paru, namun kondisi tersebut dapat menyebabkan obstruksi. Gejala tersebut bermanifestasi sebagai dispnea, batuk, atau hemoptisis (Chaaya \& Vishnubhotla, 2017). Hubugan antara trombosis vena paru dan gagal jantung dekompensasi tidak diketahui. Trombosis vena paru dapat menyebabkan perubahan hemodinamik, biologis, dan histologis yang dapat menyebabkan dekompensasi gagak jantung kronis. Selain itu akibat dari trombosis vena paru sistem drainase sirkulasi paru dapat menyebabkan beberapa masalah, termasuk perdarahan alveolar, edema paru interstitial, efusi pleura dan perubahan perfusi paru. Hal tersebut 
dapat berkontribusi terhadap gangguan perfusi ventilasi, yang mengakibatkan hipoksemua yang menjadi faktor utama gagal jantung dekompensasi akut (El et al., 2017).

\section{Kasus B}

Pada kasus B, menjelaskan bahwa pasien datang dengan memiliki berbagai macam faktor resiko dari gagal jantung diantaranya adalah hipertensi, moderete aortic stenosis, penyakit arteri koroner (coronary arteri disease), dan riwayat okulasi bypass arteri koroner. Salah satu faktor resiko terpenting yang dapat memicu terjadinya disfungsi miokard dan gagal jantung yaitu hipertensi pasien yang tidak terkontrol sehingga dapat meningkatkan afterload ventrikel kiri dan tekanan diastolik ventrikel kiri. Selain ditemukannya beberapa faktor saat tiba di rumah sakit pasien mengalami odema ekstremitas bawah yang menunjukkan bahwa pasien mengalami kelebihan volume cairan. Pada saat dirawat di ICU pasien mengalami gangguan pernafasan sehingga pasien menerima terapi oksigen sebanyak 10L/ menit menggunakan BiPAP (Bilevel Positive Airway Plessure) (Study \& Gheorghiu, 2017).

Kasus B menjelaskan peneliti dalam menangani masalah gangguan pernafasan yang dialami pasien dengan memberikan terapi oksigen dengan bantuan BiPAP hal ini sejalan dengan pendapat Puspita \& Fadil (2020), dimana gagal jantung akut yang berakibat kegagalan pernafasan akut memerlukan bantuan ventilator. Pemberian ventilasi non invasif tekanan positif (CPAP, BiPAP) harus dipertimbangkan pada pasien yang mengalami gangguan pernafasan (frekuensi nafas $>25 \mathrm{kali} / \mathrm{menit}$, Sp $<90 \%$ ) dan harus sesegera mungkin diberikan bantuan ventilasi guna mengurangi gangguan $O_{n}$

pernafasan dan mengurangi kejadian intubasi endotrakeal. Selain mengalami gangguan pernafasan, pada kasus dijelaskan pasien mengalami kelebihan volume cairan yang ditadai dengan nilai BNP sebelum dirawat di ICU mencapai antara 411 - $458 \mathrm{pg} / \mathrm{mL}$. Pada saat dirawat di ICU pasien mendapatkan pemasangan selang kateter untuk memantau urin output dan pasien mendapatkan terapi infus IV bumetanide untuk diuresis yang agresif. Diuresis tersebut digunakan untuk mencapai keseimbangan cairan - 2048mL selama pasien dirawat di ICU. Obat diuretik dapat meringankan gejala gagal jantung dengan meningkatkan kongesti paru, efusi pleura, dan edema ekstreminas. Hal tersebut dapat terjadi dengan mengurangi preload dan mengurangi tekanan end - diastolik ventrikel kiri (Fukata, 2020).

Terapi diuretik digunakan sebagai terapi untuk mengurangi kelebihan volume cairan merupakan terapi paling umum yang diterapkan untuk meningkatkan fungsi kardiovaskuler. Pasien yang dilakukan pengobatan diuretik tidak dianjurkan untuk diberikan cairan intravena. Meskipun telah ada beberapa penelitian tentang manfaat pemberian larutan hipertonik dalam jumlah kecil, pasien dengan gagal jantung tetap harus melakukan pembatasan cairan dan tidak direkomendasikan diberikan cairan intravena (Bikdeli et al., 2015). Pemberian diuretik intravena akan menyebabkan terjadinya venodilatasi, obat diuretik juga dapat meningkatkan produksi prostaglandin inhibitor seperti obat antiflamasi nonsteroid, oleh sebab itu harus dihindari bila memungkinkan berupa injeksi sesuai dengan evidence based medicine. Selain itu pemberian diuretik secara parenteral diindikasikan pada gagal jantung berat dan edema paru akut (Sari, Yonata, \& Swadharma, 2016).

\section{Kasus C}

Lain halnya dengan kasus C, dimana pasien ketika datang ke RS tersebut telah mengalami gagal jantung refrakter dan miokard infrak yang telah terjadi 3 bulan yang lalu setelah onset miokard infrak pasien mengalami atrial flutter. Pada saat itu pasien memerlukan pemasangan intra aortic balloon pumping dan filtrasi hemodinamik kontinue pada fase akut dan alat bantu nafas non - invasif positive pressure ventilation. Pasien mengalami dispnea dan kelelahan ketika mendapatkan terapi inotrop intravena dan terapi medis lainnya. Pasien kemudian menerima alat bantu nafas adaptive servo ventilation untuk membantu dan mempertahankan pernafasan pasien. 
Namun ketika alat tersebut dipasangkan, pasien mengalami penurunan denyut jantung (HR) dari $100 \mathrm{bpm}$ menjadi $80 \mathrm{bpm}$ pada saat itu pasien masih mengalami atrial flutter. Setelah pasien menjalani 6 bulan perawatan atrial flutter dirubah menjadi irama sinus dengan HR saat istirahat 60 bpm. Setelah itu gagal jantung pasien semakin memburuk, pasien mengeluh dipsnea saat istirahat. Hasil ekokardiogram menunjukkan bahwa doppler gelombang pulse dari aliran trans mitral memiliki pola restriktif yang menunjukkan peningkatan tekanan end diastolik left ventrikel. Kemudian peneliti menduga bahwa pasien mengalami bradikardia relatif (bradikardia sinus ringan $60 \mathrm{bpm}$ ) yang menyebabkan kondisi pasien memburuk (Nagatomo et al., 2019). Bradikardia relatif sendiri diartikan sebagai istilah yang menggambarkan mekanisme dimana terdapat disosiasi antara pulse dan suhu atau adanya kegagalan denyut nadi yang meningkat ketika suhu lebih dari 102 (Ye et al., 2018).

Pada kasus dijealskan peneliti melakukan pemasangan kateterisasi jantung kanan (RHC) untuk mengetahui bagaimana hemodinamik dapat dipengaruhi oleh HR. Kemudian pasien dilakukan pemasangan alat pacu jantung. Menurut penelitian (Ye et al., 2018) sel sel alat pacu jantung dapat bertindak sebagai target untuk sitokin inflamasi yang dapat membuat adanya perubahan dinamika denyut jantung ataupun respon terhadap neurotransmitter selama peradangan sistemik.

Salah satu alat pacu jantung yang direkomendasikan adalah intra aortic baloon pump (IABP). IABP direkomendasikan untuk digunakan dalam jangka pendek untuk managemen syok kardiogenik, angina tidak stabil yang sulit disembuhkan, atau takikardia ventrikel refraktori atau keras, maupun untuk mendukung operasi jantung sebelum maupun pasca operasi. IABP merupakan pengobatan gangguan fungsi jantung, yang memiliki keterbatasan yang terkandung dalam conterpulsation sehingga semakin lemah ventrikel kiri (LV) semakin berkurang juga keefektifan IABP dalam menambah cardiac output. Asuhan keperawatan pasien dengan IABP berfokus pada ketepatan waktu, pencegahan komplikasi (Asber et al., 2020). Diharapkan dengan penanganan pasien yang tepat dapat mengoptimalkan heart rate pasien dan menghindari adanya bradikardi.

\section{Kasus D}

Kasus D menjelaskan seorang pasien dirawat karena mengalami sesak nafas selama beberapa hari dan hasil elektrokardiogramnya menunjukkan adanya fibrilasi atrium dengan blok ventrikel atrium dan terdapat bradikardia simtomatik, pasien kemudian didiagnosis dilated cardiomyopaty. Selain terjadi disfungsi jantung, pasien mengalami kelemahan pada otot tungkai atas lebih tepatnya terjadi kelemahan pada gluteus maximus. Setelah itu pasien menjalani latihan uji kardiopulmoner terbatas dengan menganalisis gas metabolik. Latihan tersebut menunjukkan adanya penurunan dalam penyerapan oksigen yang ditunjukkan dengan adanya kompromi yang signifikan terhadap toleransi latihan dan juga pasien mengalami kelemahan otot pernafasan yang parah. Latihan tersebut dilakukan dengan cara mengevaluasi otot pernafasan dan mengukur tekanan inspirasi maksimal (MIP) dan tekanan ekspirasi maksimal (MEP) (Taya \& Amiya, 2019). Kelemahan otot pernafasan secara umum dipengaruhi oleh adanya penurunan volume tidal (TV) selama olahraga. Telah dilakukan penelitian bahwa kelemahan otot pernafasan dialami oleh sekitar $50 \%$ pasien jantung yang disebabkan oleh atrofi otot karena gagal jantung itu sendiri (Hamazaki et al., 2018). Biasanya pasien dengan gagal jantung melakukan pelatihan otot inspirasi (IMT) yang melibatkan latihan otot diafragma dengan fungsi inspirasi, yang dapat meningkatkan kekuatan dan daya tahan otot, kapasitas fungsional, dan respons ventilator untuk berolahraga dan mendorong pemulihan kemampuan motorik. Efek dari pelatihan otot pernafasan pada pasien gagal jantung yaitu meningkatkan kekuatan otot inspirasi, konsumsi oksigen puncak (VO2), kualitas hidup, dan berkurangnya dispnea (Bsn, 2018).

Pasien gagal jantung yang dirawat di ICU kebanyakkan mendapatkan alat bantu nafas dengan ventilasi mekanik invasif (MV) sebagai intervensi terpenting untuk memenuhi kebutuhan oksigen dan juga menyelamatkan nyawa pasien selama perawatan. Namun ventilasi mekanik dapat mengakibatkan gangguan kekuatan dan daya tahan otot inspirasi jika pemakaian berkepanjangan $(>24$ 
jam). Pemakaian berkepanjangan juga dapat mengakibatkan disfungsi diafragma yang berakibatkan sulitnya pelepasan alat (penyapihan). Selain itu, kelemahan otot inspirasi dapat berkontribusi pada peningkatan dispnea pada pasien yang baru melakukan penyapihan ventilasi mekanik. Pelatihan otot inspirasi (IMT) dapat digunakan sebagai intervensi bagi pasien ICU agar pasien dapat meningkatkan kekuatan otot inspirasi dan mempercepat proses penyapihan ventilasi mekanik (Bissett, Science, \& Leditschke, 2018). Hal tersebut sesuai dengan kasus bahwa pasien setelah menjalani latihan tidak ditemukan adanya nilai peptida natriuretik obat (BNP) dan gangguan pernafasan pada pasien berkurang (Taya \& Amiya, 2019). Hal ini berarti pasien mampu meningkatkan kekuatan otot inspirasi dan juga secara tidak langsung pasien berkontribusi untuk mengurangi jumlah dan derajat komplikasi pernafasan seperti pneumonia atau atelektasis.

\section{Kasus E}

Seorang pasien mengalami sesak nafas dengan frekuensi nafas 30 kali/ menit dengan menggunakan otot bantu pernafasan, SpO2 98\% dengan terpasang nasal kanul 4 liter/ menit. Pasien tampak menggunakan pernafasan cuping hidung. Peneliti memberikan posisi semifowler untuk membuat keadaan pasien lebih rileks (Mugihartadi \& Handayani, 2020). Pada kasus E peneliti tidak menjelaskan secara spesifik bagaimana kondisi pasien saat itu, tidak dijelaskan juga mengenai pemeriksaan penunjang dan terapi farmakologi pasien. Mungkin peneliti hanya ingin berfokus pada terapi oksigenasi dan pola pernafasan pasien dengan gagal jantung.

Pada kasus setelah diberikan terapi oksigenasi pasien menunjukkan perubahan pola nafas dan frekuensi pernafasan pasien berada dalam batas normal. Hal tersebut sesuai dengan penelitian Nael et al. (2019) bahwa terapi oksigen memang direkomendasikan untuk pasien dengan saturasi oksigen perifer $(\mathrm{SpO} 2)<90 \%$ atau tekanan parsial oksigen $(\mathrm{PaO} 2)<60 \mathrm{mmHg}$, untuk dapat memperbaiki hipoksemia dan atau untuk meringankan gejala yang berhubungan dengan hipoksemia. Pemberian segera terapi oksigen dengan aliran tinggi dianjurkan untuk pasien dengan acute heart failure yang kritis dengan gangguan pernafasan akut.

Penggunaan oksigen dalam kisaran normal - rendah, dapat mencegah terjadinya hipoksemia dan mengurangi ketidakcocokan pasokan dan permintaan oksigen dalam miokard infark sehingga ukuran infark dapat dikurangi dan meminimalkan terjadinya komplikasi. Sedangkan pada penggunaan oksigen dengan batas normal - tinggi, terapi oksigen dapat mengakibatkan hiperoksemia (tingginya tekanan oksigen dalam darah) yang dapat berpontesi menyebabkan disfungsi kontraktil miokard toksik, meningkatnya stres oksidatif, cedera reperfusi, dan akhirnya kematian sel miokard (James et al., 2019). Sedangkan menurut Sepehrvand \& Ezekowitz (2016), pemberian terapi oksigen direkomendasikan untuk mengelola hipoksemia (saturasi oksigen perifer $<90 \%$ hingga $94 \%$ atau pasien dengan tekanan oksigen arteri parsial $<60 \mathrm{mmHg}$ ) selain itu pemberian terapi oksigen digunakan untuk meningkatkan oksigen jaringan miokard yang sakit. Namun pemberian terapi oksigen yang berlebihan dapat merusak fungsi jantung. Terapi oksigenasi digunakan sebagai terapi untuk memenuhi kebutuhan oksigen bagi pasien acute heart failure, namun pedoman dalam pemberian dan tentang penggunaannya masih kurang dan perlu penelitian lebih lanjut.

Pada kasus dijelaskan bahwa peneliti memberikan intervensi pemberian posisi semi fowler pada pasien guna memberikan posisi yang rileks. Intervensi tersebut merupakan intervensi yang tepat dilakukan agar pasien merasa lebih mudah dalam memenuhi kebutuhan oksigen. Hal ini didukung oleh Wijayati \& Ningrum (2019), yang menjelaskan bahwa pemberian posisi semi fowler merupakan tindakan yang efektif untuk meminimalisir terjadinya resiko penurunan pengembangan dada. Pemberian posisi semi fowler dilakukan pada pasien yang mengalami sesak nafas yang beresiko mengalami penurunan saturasi oksigen seperti kardiopulmonari dengan derajat kemiringan 30 - 45 .

Pasien dengan gagal jantung bisanya mengalami edema pulmoner. Pasien yang mengalami edema pulmoner memiliki ketebalan memberan alveoli yang meningkat, cairan atau edema yang 
menghambat prosess difusi karena gas memerlukan waktu yang cukup lama dalam melewati membran alveoli, sehingga dapat mengakibatkan lambatnya proses difusi. Pertukaran gas yang lambat dapat mengganggu proses pengiriman oksigen ke jaringan.

\section{KESIMPULAN}

Terapi oksigenasi dalam memaksimalkan kebutuhan oksigen dan respirasi pasien gagal jantung dapat dilakukan dengan alat bantu ventilasi dan pengaturan posisi pasien diantaranya dengan alat bantu non invasif $\mathrm{CPAP}$, BiPAP, alat bantu nafas adaptive servo, dan terapi oksigen dengan nasal kanul sesuai dengan kondisi dan komplikasi pasien. Pengaturan posisi dalam bentuk posisi semifowler dengan kemiringan $30-45$ juga merupakan intervensi yang tepat.

\section{DAFTAR PUSTAKA}

Asber, S. R., Shanahan, K. P., Lussier, L., Didomenico, D., Davis, M., Eaton, J., ... Kapur, N. K. (2020). Nursing Management of Patients Requiring Acute Mechanical Circulatory Support Devices. Critical Care Nurse, 40(1), 1-11. https://doi.org/https://doi.org/10.4037/ccn2020764

Bikdeli, B., Dharmarajan, K., Mody, P., \& Horwitz, L. I. (2015). Intravenous Fluids in Acute Decompensated Heart Failure. JACC, 3(2). https://doi.org/10.1016/j.jchf.2014.09.007

Bissett, B., Science, A., \& Leditschke, I. A. (2018). Australian Critical Care Inspiratory Muscle Training for Intensive Care Patients : A Nultidisciplinary Practical Guide for Clinicians. Australian Critical Care, 1-7. https://doi.org/10.1016/j.aucc.2018.06.001

Brahmbhatt, D. H., \& Cowie, M. R. (2018). Heart Failure: Classification and Pathophysiology. Medicine, 1-7. https://doi.org/10.1016/j.mpmed.2018.07.004

Bsn, J. W. (2018). Effects of Inspiratory Muscle Training in Chronic Heart Failure Patients : A Systematic Review and Meta-Analysis. Congetinal Heart Disease, (September 2017), 1-9. https://doi.org/10.1111/chd.12586

Chaaya, G., \& Vishnubhotla, P. (2017). Pulmonary Vein Thrombosis : A Recent Systematic Review Pathophysiology, 9(1), 1-14. https://doi.org/10.7759/cureus.993

Dharmarajan, K., \& Rich, M. W. (2017). Epidemiology, Pathophysiology, and Prognosis of Heart Failure in Older Adults. Heart Failure Clinics, 13(3), 417-426. https://doi.org/10.1016/j.hfc.2017.02.001

El, J., Milouchi, S., Ferjani, S., Abid, O., Ghourabi, A., \& Sghaier, A. (2017). Idiopathic Pulmonary Vein Thrombosis: An Unexpected Cause of Respiratory Distress and Acute Heart Failure . A Case Report and Review of the Literature. African Journal of Emergency Medicine, 8-11. https://doi.org/10.1016/j.afjem.2017.05.008

Fukata, M. (2020). Acute Decompensated Heart Failure in Patients with Heart Failure with Reduced Ejection Fraction. Heart Failure Clinics. https://doi.org/10.1016/j.hfc.2019.12.007

Hamazaki, N. O., Masuda, T. A., Kamiya, K. E., Matsuzawa, R. Y., Nozaki, K. O., Maekawa, E. M. I., ... Ako, J. U. (2018). Respiratory Muscle Weakness Increases Dead-Space Ventilation Ratio Aggravating Ventilation - Perfusion Mismatch During Exercise in Patients with Chronic Heart Failure. Journal of the Asian Pacific Society of Respirology, 2018(October). https://doi.org/10.1111/resp.13432

James, S. K., Erlinge, D., Herlitz, J., Alfredsson, J., Koul, S., Kellerth, T., ... Hofmann, R. (2019). Effect of Oxygen Therapy on Cardiovascular Outcomes in Relation to Baseline Oxygen Saturation. JACC: Cardiovascular Interventions. https://doi.org/10.1016/j.jcin.2019.09.016

Mugihartadi, \& Handayani, M. R. (2020). Pemberian Terapi Oksigenasi dalam Mengurangi Ketidakefektifan Pola Nafas pada Pasien Congestive Heart Failure (CHF) di Ruang ICU/ ICCU RSUD DR. Soedirman Kebumen. Nursing Science Jurnal (NSJ), 1(1), 1-6.

Nael, J., Ruggiu, M., Bailleul, C., Ortuno, S., Diehl, J., Vimpère, D., ... Aissaoui, N. (2019). Impact of Hyperoxia on Patients Hospitalized in An Intensive Care Unit for Acute Heart Failure. Archives of Cardiovascular Diseases, 20-25. https://doi.org/10.1016/j.acvd.2019.09.003

Nagatomo, D., Kotooka, N., \& Yoshioka, G. (2019). Strategy for Estimating Optimal Heart Rate in 
Refractory Heart Failure with Relative Sinus Bradycardia : A Case Report. Journal of Cardiology Cases, 10-13. https://doi.org/10.1016/j.jccase.2019.12.003

Puspita, D., \& Fadil, M. (2020). Penggunaan Ventilasi Mekanik pada Gagal Jantung Akut. Jurnal Kesehatan Andalas, 9(Supplement 1), 194-203.

Sari, P. D., Yonata, A., \& Swadharma, B. (2016). Penatalaksanaan Gagal Jantung NYHA II disertai Pleurapneumonia pada Laki-laki Usia 38 Tahun. Jurnal Medula Unila, 6, 114-119.

Sepehrvand, N., \& Ezekowitz, J. A. (2016). Oxygen Therapy in Patients With Acute Heart Failure. JACC: Heart Failure, 4(10), 783-790. https://doi.org/10.1016/j.jchf.2016.03.026

Study, A. C., \& Gheorghiu, V. (2017). Identification and Prevention of Secondary Heart Failure: American Association of Critical-Care Nurses, 37(4), 29-37. https://doi.org/https://doi.org/10.4037/ccn2017478

Taya, M., \& Amiya, E. (2019). Inspiratory Muscle Training for Advanced Heart Failure with LaminRelated Muscular Dystrophy. Journal of Cardiology Cases, 9-11. https://doi.org/10.1016/j.jccase.2019.09.007

Wijayati, S., \& Ningrum, D. H. (2019). Pengaruh Posisi Tidur Semi Fowler $45^{\circ}$ terhadap Kenaikan Nilai Saturasi Oksigen pada Pasien Gagal Jantung Kongestif di RSUD Loekmono Hadi Kudus. Medica Hospitalia: Journal of Clinical Medicine, 6(1), 13-19.

Ye, F., Winchester, D., Stalvey, C., Jansen, M., Lee, A., Khuddus, M., ... Yale, S. (2018). Proposed Mechanisms of Relative Bradycardia. Medical Hypotheses, 119(July), 63-67. https://doi.org/10.1016/j.mehy.2018.07.014 